\title{
Da tradução à criação literária: os contos de fadas reescritos por Angela Carter
}

Anna Olga Prudente de Oliveira*

\author{
A tradução é o mais íntimo ato de \\ leitura. \\ GAYATRI SPIVAK
}

\section{Introdução}

Escritora inglesa aclamada em seu país, Angela Carter (1940-1992) ainda não é tão conhecida no sistema literário brasileiro; apenas alguns de seus romances foram publicados no Brasil ao final da década de 1980 e início dos anos 1990. E, mais recentemente, temos a publicação de contos de fadas compilados pela escritora e de contos de sua própria autoria, a obra The Bloody Chamber and Other Stories, publicada em edições distintas por duas editoras brasileiras. Quatro livros foram publicados pela editora Rocco, encontrando-se, entretanto, fora de catálogo atualmente. Por essa editora, temos os romances A paixão da nova Eva (The Passion of New Eve), em tradução de Eliana Sabino (1987); As infernais máquinas de desejo do Dr. Hoffman (The Infernal Desire Machines of Dr. Hoffman), em tradução de Afonso Felix de Sousa (1988); e Noites no circo (Nights at the Circus), em tradução de Claudia Martinelli Gama (1991). E, também publicado pela Rocco, temos o livro de contos, a mais célebre de suas obras, The Bloody Chamber and Other Stories, intitulado O quarto do Barba-Azul na tradução de Carlos Nougué (1999). Pela Companhia das Letras, foi publicado o livro de contos de fadas compilados pela escritora, Angela Carter's Book of Fairy Tales, em tradução de Luciano Vieira Machado, com o título 103 Contos de fadas (2007), e posteriormente em nova edição, pela Penguin Classics - Companhia das Letras, contendo uma

${ }^{*}$ Universidade Federal do Paraná 
seleção desses contos, em livro intitulado A menina do capuz vermelho e outras histórias de dar medo (2011).

Mais recentemente, em 2017, foi publicado A câmara sangrenta e outras histórias, pelo clube de livros TAG em parceria com a editora Dublinense, em um projeto editorial realizado exclusivamente por mulheres, com curadoria da escritora Marina Colasanti e tradução de Adriana Lisboa. Utilizo essa edição brasileira da obra The Bloody Chamber and Other Stories, ao abordar a noção de poética translacional, desenvolvida por Martine Hennard Dutheil de la Rochère (2013), como chave de leitura do processo de escrita literária de Angela Carter.

Neste artigo, busca-se refletir sobre a relevância da atividade tradutória para a criação literária da escritora inglesa, com um recorte considerando especificamente seu trabalho de tradução dos contos de Charles Perrault (The Fairy Tales of Charles Perrault, 1977), o qual forneceu as bases e o contraponto para a elaboração de seus próprios contos de fadas (The Bloody Chamber and Other Stories, 1979), escritos a partir das histórias fixadas na literatura escrita pelo autor francês do século XVII, entre outros (HENNARD DUTHEIL DE LA ROCHÈRE, 2013, p.1). A análise volta-se mais detidamente para a história de "Barba Azul" ("La Barbe Bleue"), de Charles Perrault, a qual Carter traduz e assimila para elaborar sua reescrita, The Bloody Chamber, o conto que dá título a seu livro.

\section{E se...? abrindo portas com Angela Carter}

Para abordar a autora e sua obra The Bloody Chamber, observa-se, em primeiro lugar, que os Estudos de Contos de Fadas (Fairy-Tale Studies) têm seu desenvolvimento, enquanto área de pesquisa, ligado fortemente aos processos de reescrita de contos de fadas, nos quais Angela Carter exerce papel central na década de 1970, como tradutora e também como crítica, editora e reescritora, e ainda, de forma indireta, no que diz respeito à própria recepção crítica polarizada de sua obra autoral, criada a partir de contos de fadas (HENNARD DUTHEIL DE LA ROCHÈRE, 2013, p.11). E, como aponta Donald Haase, no prefácio de Fairy Tales and Feminism, os Estudos de Contos de Fadas inspirados por uma perspectiva feminista 
evitam uma visão monolítica do conto de fadas centrado na mulher; permitem uma ambiguidade em relação a contos escritos por mulheres e uma ambivalência em sua recepção; exploram novos textos e contextos; e reconsideram os limites nacionais, culturais e de gênero que moldaram os contos de fadas e com frequência restringiram nossa compreensão sobre os mesmos. ${ }^{1}$ (HAASE, 2004, p. x)

Carter esteve à frente dessa cena inicial de desenvolvimento do campo dos Estudos Feministas de Contos de Fadas (Feminist Fairy-Tale Studies), tendo sido uma autora de contos que dialogam com o folclórico e o tradicional, imprimindo, no entanto, uma radicalidade quanto à perspectiva feminista, rompendo paradigmas de representação de gênero, sem limitarse, contudo, a agendas ou pautas específicas do movimento feminista de sua época. Carter, portanto, não rejeita os contos de fadas pelas ideias preconcebidas a respeito do sexismo ou do machismo neles expressos, mas, ao contrário, explora os contos, passando a estudá-los, podendo dessa forma perceber a complexidade de histórias como os Contos da Mamãe Gansa publicados por Charles Perrault no século XVII. Desse modo, em sua obra, a partir de histórias e personagens como "Chapeuzinho Vermelho", "Barba Azul”, "Gato de Botas", Carter procede a uma total reformulação dos contos nos quais se inspira, propondo "extrair o contexto latente das histórias tradicionais e usá-las como o começo de novas histórias" (CARTER, 2017, catálogo, p.14).

Em um projeto feminista de "desmitificação" (HENNARD DUTHEIL DE LA ROCHÈRE, 2013, p.2), em que revisita o passado cultural e literário acrescentando sua perspectiva do presente, Carter nos abre portas para imaginarmos: e se a menina do capuz vermelho quisesse conhecer o lobo, em vez de temê-lo? E se Barba Azul fosse um esteta, colecionador de arte (e de mulheres-objeto-de-arte), e não somente um assassino em série? É o que iremos ver nos dez contos de A câmara sangrenta e outras histórias, inspirados em contos de fadas tradicionais e populares, folclore e mitologia: "A câmara

\footnotetext{
${ }^{1}$ Tradução minha, assim como as demais citações de textos em língua estrangeira. No original: [...] eschew a monolithic view of the woman-centered fairy tale; allow for ambiguity within female-authored tales and for ambivalence in their reception; explore new texts and contexts; and reconsider the national, cultural, and generic boundaries that have shaped the fairy tale and often limited our understanding of it.
} 
sangrenta", "O Sr. Lyon faz a corte", "A noiva do tigre", "O Gato de Botas", "O Rei dos Elfos", "A filha da neve", "A senhora da casa do amor", "O lobisomem", "A companhia dos lobos" e "A Loba Alice".2

Abrindo portas fechadas pelas chaves do patriarcado e das ideias preconcebidas, Carter desvenda gabinetes secretos em uma leitura íntima dos contos de fadas e do folclore, uma leitura tradutora; uma leitura que traduz e cria o novo, a partir da repetição, em suas traduções e (re)escritas. É no amálgama entre o traduzir e o (re)escrever ou (re)criar, enquanto atividades intelectuais e artísticas cujas fronteiras são permanentemente porosas, que se encontra a obra de Angela Carter.

\section{Uma ebulição criativa: novas leituras de textos antigos}

A obra multidimensional de Carter, como sugere Marie Mulvey-Roberts (2019, p.1), “é como uma série de quartos instigantes ou gabinetes de curiosidades textuais", ${ }^{3}$ que vão sendo abertos pelos leitores que adentram esses espaços; obra iconoclasta, a qual, não sendo possível enquadrar em determinado gênero ou estilo literário, podemos compreender como uma literatura que faz uso sistemático de inúmeras referências, leituras e entrecruzamentos, com elementos que permeiam ou assimilam o gótico, a ficção científica, o surrealismo, os contos de fadas, o folclore, a mitologia e a religião, a filosofia, as artes plásticas e visuais.

Autoproclamada feminista e ateísta - "sim! [...] é preciso empunhar a bandeira"4 (CARTER, Interview with Lorna Sage, 1977, apud MULVEYROBERTS, 2019, p.145) -, Carter não pretende deixar-se domar, busca apropriar-se de paradigmas ou modelos conhecidos para criar uma literatura própria, liberta de amarras conceituais. Sua inventividade atravessa seus romances, contos, peças de rádio, traduções, literatura para crianças, poesias, textos não-ficcionais e jornalísticos, e "[s]ua linguagem descritiva e intensamente visual mistura-se com o filosófico e o abstrato

\footnotetext{
2 No original: "The Bloody Chamber", “The Courtship of Mr Lyon”, “The Tiger's Bride”, “Puss-in-Boots", "The Erl-King", "The Snow Child", "The Lady of the House of Love", "The Werewolf", "The Company of Wolves", "Wolf-Alice".

${ }^{3}$ No original: [...] is like a series of curious rooms or textual cabinet of curiosities.

${ }^{4}$ No original: yes! [...] you have to keep the flag flying,
} 
através de um jogo de ideias pós-modernista"5 (MULVEY-ROBERTS, 2019, p.2). Como ela mesma instiga, recorrendo às Investigações Filosóficas de Wittgenstein, em uma das epígrafes de As infernais máquinas de desejo do Dr. Hoffman: "(Lembre que às vezes pedimos definições em função da sua forma, e não do conteúdo. Nosso requisito é arquitetural: a definição é uma espécie de cumeeira para o suporte de coisa nenhuma.)" (CARTER, 1988, grifos meus, p.7).

A ficção é para Carter uma forma de trabalhar ideias e desenvolver argumentos. Uma das metáforas que utiliza para pensar a literatura é a partir de sua compreensão de que a leitura é também uma atividade criativa, assim como a escrita, alçando o processo de leitura, e de tradução enquanto leitura privilegiada, ao patamar da escrita.

Ler é uma atividade tão criativa quanto escrever, e grande parte do desenvolvimento intelectual depende de novas leituras de textos antigos. Sou totalmente a favor de colocar vinho novo em velhas garrafas, especialmente se a pressão do vinho novo fizer as velhas garrafas explodirem. ${ }^{6}$ (CARTER, Notes from the Front Line, p.37, grifos meus, apud HENNARD DUTHEIL DE LA ROCHÈRE, 2013, p.2).

Confrontando a parábola bíblica do "vinho novo em odres velhos"7, essa forma de leitura ativa, em ebulição, é o que move Carter tanto como tradutora do francês para o inglês quanto como escritora de sua própria obra autoral, na qual se misturam literaturas, línguas e linguagens diversas.

\section{Carter e Perrault: cronistas de seu tempo}

Contra a corrente feminista de sua época, Carter não rechaça os contos de fadas, evitando rotulá-los como obras datadas expressando valores

\footnotetext{
${ }^{5}$ No original: Her descriptive and intensively visual language merges with the philosophic and the abstract through a post-modernist play of ideas.

${ }^{6}$ No original: Reading is just as creative an activity as writing and most intellectual development depends upon new readings of old texts. I am all for putting new wine in old bottles, especially if the pressure of the new wine makes the old bottles explode.

${ }^{7}$ Com interpretações diversas, a parábola, que teria sido contada por Jesus, é encontrada no Novo Testamento, em Mateus (9:17), Marcos (2:22) e Lucas (5:37-38): “E nenhum homem põe vinho novo em odres velhos; do contrário o vinho novo rompe os odres, e o vinho se derrama, e os odres se perdem; mas vinho novo deve ser colocado dentro de odres novos" (Marcos, 2:22, Bíblia King James).
} 
misóginos e machistas. Ela compreende Charles Perrault, por exemplo, como um cronista de seu tempo, alguém que consegue explorar a mundanidade dos contos de fadas, algo que ela própria buscará realizar em sua (re)escrita dos mesmos. Desse modo, complexifica a leitura da obra perraultiana, assim como o faz com outras obras e autores. Considerando o autor do século XVII uma voz que refletia os temas mundanos do período, Carter o vê como um narrador crítico e irônico dos costumes e modos de vida de seu tempo. Perrault, através de sua Mamãe Gansa, é aquela figura que fala a seus leitores ou ouvintes com o uso de certos subterfúgios para elaborar comentários sociais, sempre ao final dando uma piscadela a seu público, aprendiz (ou cúmplice) da história contada e da ironia nas entrelinhas.

Essa leitura torna-se possível quando Carter traduz do francês para o inglês, em 1977, o livro de Perrault, Histórias ou contos do tempo antigo com moralidades ou Contos da Mamãe Gansa8, contendo "A Bela adormecida no bosque”, "O Chapeuzinho Vermelho", "Barba Azul”, “O Mestre Gato ou o Gato de Botas", "As Fadas", "A Gata Borralheira (Cinderela) ou A sapatilha de vidro", "Riquete do Topete" e "O Pequeno Polegar" 9 . Além dos oito contos da Mamãe Gansa, Carter também traduz outros dois contos de Perrault, escritos inteiramente em verso, "Os desejos ridículos" e "Pele de Asno"10. Assim, em sua tradução, no livro intitulado The Fairy Tales of Charles Perrault, temos dez contos, todos traduzidos em prosa.

Perrault pode ser visto também como um reescritor, uma vez que seus contos foram elaborados a partir de algumas histórias populares da tradição da oralidade (ou eventualmente registradas na literatura escrita), as quais foram recriadas de acordo com suas perspectivas literárias e ideológicas, passando a fazer parte da literatura escrita (OLIVEIRA, 2020, p. 95-98). Em seu processo de retomada de histórias populares, embora tenha mantido a forma narrativa, a simplicidade e objetividade do conto popular, Perrault procedeu a uma ampla reescrita das histórias e até a uma censura

\footnotetext{
${ }^{8}$ No original: Histoires ou Contes du temps passé avec des Moralités ou Contes de ma Mère l'Oye.

${ }^{9}$ No original: "La Belle au bois dormant", "Le Petit Chaperon rouge", "La Barbe bleue”, "Le Maître Chat ou Le Chat botté", “Les Fées", "Cendrillon ou La Petite Pantoufle de verre", "Riquet à la houppe", "Le Petit Poucet".

${ }^{10}$ No original: "Les Souhaits ridicules" e "Peau d'Âne".
} 
de suas fontes, como vemos em "A Bela adormecida": no primeiro livro europeu contendo contos de fadas, publicado em Veneza entre 1550 e 1553 por Straparola, a personagem concebia e dava à luz durante seu sono, enquanto o príncipe de Perrault era um gentleman que jamais teria tal comportamento (CARTER, 2008, p.76). Em Perrault, não há sequer um beijo do príncipe (cena comum em diversas versões), uma vez que a Bela desperta simplesmente porque o tempo do feitiço havia chegado ao fim.

Escritos em prosa, os contos da Mamãe Gansa de Perrault contêm ao final da história uma espécie de conclusão ou comentário do autor sobre o que foi narrado, as chamadas moralidades, pequenos poemas em verso que complementam a narrativa em prosa. Para Carter,

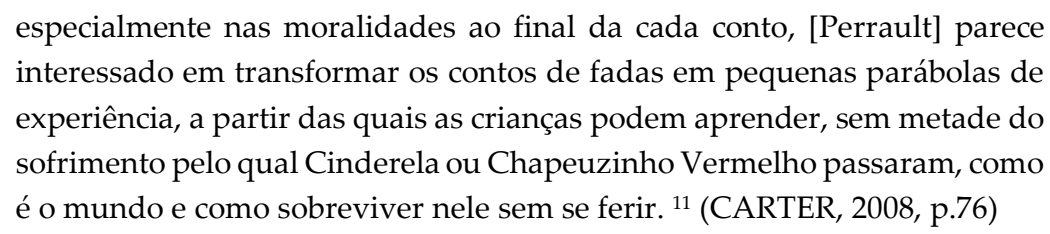

Como será visto adiante, Carter traduz as moralidades de Perrault, possibilitando que seu público leitor conheça essa particularidade dos contos de fadas do autor francês do século XVII.

Inserida na voga dos contos de fadas da corte de Luís XIV (CARTER, 2008, p.74), a publicação dos contos de Perrault em 1697, contendo uma dedicatória à Mademoiselle, sobrinha do rei, apresenta uma ambiguidade em relação ao público a que se destina. Embora à época não houvesse ainda uma literatura definida como infantil ou infantojuvenil, Perrault apresenta uma escrita que mimetiza o "popular" e também uma "simplicidade infantil", além de excluir elementos mais ofensivos, presentes em outras versões das histórias; por outro lado, seus contos contêm ironia e certo erotismo jocoso que certamente se dirigia a adultos e não a crianças (HAASE, 2008, p. 184-186). Com uma dupla valência, entre uma simplicidade acessível

\footnotetext{
${ }^{11}$ No original: Especially in the moral tags at the end of each tale he seems concerned in turning the fairy tales into little parables of experience from which children can learn, without half the pain that Cinderella or Red Hiding Hood endured, the way of the world and how to come to no harm in it.
} 
e sutilezas a serem descobertas, Perrault adentra com sucesso na cena dos salões literários, nos quais as conteuses apresentavam seus contos de fadas.

\begin{abstract}
[A] alta sociedade da época privilegia o equívoco: é a ela que se dirigem as pitadas de humor, as expressões espirituosas (visando, sobretudo, as mulheres) e as alusões silenciosas que salpicam todos os textos, como, por exemplo, os eufemismos d'A Bela Adormecida no Bosque e os duplos sentidos do Chapeuzinho Vermelho (COLLOGNAT-BARÈS; BRUNET; DRONNE, 2016, p.11).
\end{abstract}

Desse modo, embora os contos de Perrault tenham se tornado posteriormente clássicos da literatura infantojuvenil, podemos considerar que o público principal de Perrault era formado por adultos, e que seu direcionamento a crianças serviu como instrumento para introduzir contos populares na cultura literária (HAASE, 2008, p.186).

Importante observar que, ao tornarem-se clássicos da literatura infantojuvenil, essas histórias com origem na oralidade passam a ser consideradas um "tesouro" da humanidade, como observa a escritora, também tradutora de Perrault, Ana Maria Machado (PERRAULT, 2010, p.13), entendidas como universais, como se expressassem ideias ou valores comuns a todos. Muito difundida pela leitura psicanalítica de Bruno Bettelheim, tal perspectiva universalista sobre os contos de fadas passa a exercer enorme influência sobre o entendimento acerca do gênero, desde a década de 1970, quando foi lançado seu livro The Uses of Enchantment: The Meaning and Importance of Fairy Tales (1976), traduzido no Brasil por Arlene Caetano com o título A psicanálise dos contos de fadas (2012, 27ª reimpressão). Contrapondo-se a essa visão universalista, o entendimento de que os contos têm raízes socioculturais específicas e expõem valores historicamente determinados (HAASE, 1999, p.359) consegue ampliar o debate, tanto em relação ao gênero literário quanto às funções que este pode exercer em épocas ou sociedades distintas (por exemplo, literatura infantil, juvenil ou adulta etc.).

Angela Carter distancia-se tanto de uma perspectiva universalizante, tal como a adotada pela visão psicanalítica, quanto de concepções avaliativas, que prejulgavam os contos como peças circunscritas a valores 
patriarcais e, por conseguinte, não merecedoras de atenção. Portanto, com sua leitura de Perrault, Carter realiza um duplo ataque, primeiramente, desfazendo um nó, ao ler os textos, não aceitando ideias preconcebidas sobre os mesmos; com esse primeiro movimento, que já não é simples ou livre de controvérsia, pode então descobrir um autor e um gênero, o qual não representa apenas um mundo mágico ou feérico, mas também uma forma de conhecimento de mundo, e uma forma de arte, a partir das experiências sociais e culturais vivenciadas pelo escritor francês do século XVII. Assim, Carter faz uma distinção entre mitos culturalmente estabelecidos, como o da Cinderela ou da Bela Adormecida, e as histórias (e o modo de contá-las) elaboradas por Perrault, nas quais encontramos essas personagens, esses mitos personificados (HENNARD DUTHEIL DE LA ROCHÈRE, 2013, p.20).

\section{A nova Mamãe Gansa: subversão ou diálogo?}

Em sua "Introdução" aos contos de Perrault traduzidos por Carter, Jack Zipes questiona a atração da escritora inglesa pela leitura e tradução dos contos do autor francês do século XVII, em sua perspectiva, um autor "conservador" que refletia uma situação social muito distinta da realidade que ela vivenciava no auge do movimento feminista da década de 1970 (ZIPES, 2008, p. xix). Zipes considera que as transformações realizadas por Carter em sua tradução representam uma subversão aos contos de fadas clássicos. O consenso crítico tem na noção de subversão, como visto em Zipes, um dos mais influentes pesquisadores do campo dos Estudos de Contos de Fadas, o aparato para a compreensão da tradução e reescrita carterianas da obra de Perrault.

Tal noção pressupõe o entendimento de quebra ou ruptura com determinado paradigma; os contos expressariam certos valores, os quais seriam subvertidos por Carter em um processo de transformação das histórias e de suas possíveis mensagens a serem transmitidas. A ideia de subversão pode ser também entrevista na edição brasileira de The Bloody Chamber and Other Stories traduzida por Adriana Lisboa com o título $A$ Câmara Sangrenta e outras histórias. A tradutora menciona em seu prefácio: 


\begin{abstract}
Algumas feministas de sua época dedicavam-se a denunciar a misoginia dos contos de fadas tradicionais; Carter subverteu-os, fazendo com que as mulheres de suas histórias abraçassem a própria sexualidade e tomassem as rédeas de seu próprio destino. (CARTER, 2017, grifo meu, p.8)
\end{abstract}

Esse entendimento, portanto, pode ser visto tanto em relação à tradução dos contos de Perrault feita por Carter como também em relação a sua reescrita, sua criação literária autoral. Zipes considera que,

\begin{abstract}
junto com os contos coletados pelos irmãos Grimm, as narrativas de Perrault tornaram-se a encarnação da literatura canônica. Isto é, eles são vistos como os definitivos contos de fadas clássicos para crianças e adultos. Todavia, isso é verdade sobretudo pelo modo como mantiveram uma atitude essencialmente patriarcal em relação a papéis de gênero, códigos sociais de como cortejar, relações hierárquicas familiares e políticas, herança e governo. ${ }^{12}$ (ZIPES, 2008, p.xix)
\end{abstract}

Assim, conforme visto, entendendo Perrault como um conservador, propagador de valores patriarcais, e com uma limitada compreensão sobre as mulheres e seus papéis sociais (ZIPES, 2008, p. xii), Zipes indaga sobre os motivos que teriam levado Angela Carter a ser atraída pela obra do autor francês, e sobretudo a interessar-se em traduzi-la, na efervescência do feminismo dos anos 1970. Em sua análise, para aprofundar-se nas origens e significados dos contos de fadas, Carter teria realizado uma espécie de leitura deturpada ou uma reinterpretação do autor, para poder tornar seus contos mais palatáveis a sua sensibilidade feminista e política (ZIPES, 2008, p. $x \times v)$.

Entretanto, podemos compreender de modo distinto tanto o interesse de Carter por Perrault como o mergulho que ela faz em sua obra ao traduzilo e ao criar seus próprios contos a partir dos escritos pelo autor. Como procura demonstrar Martine Hennard Dutheil de la Rochère em Reading, Translating, Rewriting: Angela Carter's Translational Poetics, os dois escritores tinham muito mais em comum do que podemos imaginar, pois "Carter

\footnotetext{
${ }_{12}$ No original: Along with the tales collected by the Brothers Grimm, Perrault's narratives have become the incarnation of canonical literature. That is, they are regarded as the definitive classical fairy tales for children and adults. Yet, this is true primarily in the manner in which they have conserved a basic patriarchal attitude regarding gender roles, social codes of courting, hierarchical familial and political relations, inheritance, and government.
} 
alinha-se explicitamente com o projeto de Perrault, e, assim como ele, reabilita o conto de fadas como um gênero moderno por excelência" 13 (HENNARD DUTHEIL DE LA ROCHÈRE, 2013, p.16).

Carter valoriza Perrault como um escritor cuja arte literária não é artificial, ao contrário, para ela, trata-se de um autor cujos contos mantêm a simplicidade da forma e objetividade narrativa de um contador de histórias (CARTER, 2008, p.75). Ela considera que a "perfeita habilidade" e o "bom cinismo" não são qualidades muito presentes na literatura para crianças do século $X X$, a qual estava mais voltada para o fomento de uma vida imaginativa, aspecto que, como observa ironicamente, poderia indicar que a vida real estava insatisfatória (p.77). Carter, assim como Perrault, busca uma literatura que mostrasse o mundo tal como é, e com a qual as crianças pudessem ter um aprendizado sobre os próprios interesses, capacidade e coragem, perigos da negligência etc., a partir de personagens como Gato de Botas, Pequeno Polegar e Chapeuzinho Vermelho (CARTER, 2008, p.77-78).

Para Carter, os contos de fadas de Perrault têm "um estilo que prefigura o iluminismo - um estilo marcado pela concisão da narrativa (não há um grama de gordura em qualquer das histórias); precisão da linguagem; ironia; e realismo" 14 (CARTER, 2008, p.76). Tal perspectiva materialista, down to earth, sobre a forma de contar histórias tradicionalmente ligadas à fantasia, aproxima Carter de Perrault, fazendo com que essa leitoratradutora procure manter as características dos contos do escritor francês, por um lado, embora, por outro, apresente elementos contemporâneos, como não poderia deixar de ser, tratando-se de Angela Carter, como será visto.

Em sua tradução da obra de Perrault, feita por encomenda da editora Victor Gollancz, Carter estuda e pesquisa o autor e sua obra, traduzindo suas moralidades, usualmente omitidas, buscando apresentar às crianças histórias com o frescor com o qual teriam sido recebidas por seus primeiros leitores (HENNARD DUTHEIL DE LA ROCHÈRE, 2013, p.21). E é a partir

\footnotetext{
${ }^{13}$ No original: Carter explicitly aligns herself with Perrault's project, and like him she rehabilitates the fairy tale as a modern genre par excellence.

${ }^{14}$ No original: "a style that prefigures the age of enlightenment - a style marked by concision of narrative (there is not an ounce of flab on any story); precision of language; irony; and realism."
} 
de sua imersão nos contos de fadas que, concomitante a seu trabalho de tradução, Carter inicia sua (re)escrita de novos contos de fadas, seus "Novos Contos de Mamãe Gansa ("New Mother Goose Tales"), como classifica suas histórias sobre contos de fadas, as quais irão integrar a obra The Bloody Chamber and Other Stories.

Assim, as alterações realizadas por Carter em sua tradução e as histórias criadas em sua reescrita autoral podem ser compreendidas como um diálogo com o autor do século XVII, em um processo de assimilação e transformação, sendo a tradução a própria base que possibilita a reescrita. Se Perrault busca histórias já existentes na oralidade (e mesmo em alguns registros escritos) e os desenvolve a sua maneira, como um Moderno, Carter, embarcando nessa tradição do contar histórias, explora em sua reescrita autoral o que encontrou no texto francês, mas teve que deixar de lado em sua tradução para crianças: subtexto sexual e crítica social, humor adulto, alusões literárias, dentre outros elementos, os quais estão presentes em The Bloody Chamber and Other Stories (HENNARD DUTHEIL DE LA ROCHÈRE, 2013, p.19). Desse modo, a leitura que se propõe aqui é a de uma poética translacional realizada por Carter: sua "Câmara Sangrenta" constitui-se a partir do diálogo com os Contos de Perrault (entre outros contos de fadas), os quais fornecem a base de sua criação não apenas quanto à temática ou ao enredo mas, mais profundamente, referem-se à abordagem que realiza das nuances (literárias, sexuais, políticas etc.) que já permeavam a obra de Perrault, e que no século XX podem ser amplamente exploradas por uma escritora iconoclasta.

\section{Traduzindo Perrault: repetição e diferença}

Se a obra de Perrault não era dirigida a crianças, a escritora inglesa ao traduzi-la, em The Fairy Tales of Charles Perrault, volta-se para um público infantil, mantendo a tradição estabelecida pelo gênero literário dos contos de fadas a partir do século XVIII em diante. Seu interesse pela literatura infantil advém do entendimento de que a educação é uma chave para a emancipação. 
[Carter] considera os contos de Perrault propícios a seu próprio projeto, e as escolhas que fez em sua tradução permitiram que ela reivindicasse o gênero em uma época em que o conto de fadas era um tema altamente debatido nos círculos feministas. ${ }^{15}$ (HENNARD DUTHEIL DE LA ROCHÈRE, 2013, p.9)

É dessa forma que podemos compreender a manutenção das moralidades ao final das histórias, elemento literário muitas vezes suprimido em traduções e adaptações dos contos de Perrault voltadas ao público infantil. ${ }^{16}$ Para Carter, a moralidade é uma espécie de escrúpulo moral para explicar as coisas, tendo relação com o modo como as pessoas agem, não sendo, todavia, uma forma de dizer às pessoas como devem se comportar (HENNARD DUTHEIL DE LA ROCHÈRE, 2013, p.109-110).

Assim, Carter retoma as moralidades como uma forma de transmitir um conhecimento significativo para as crianças; porém, sua estratégia tradutória combina repetição, ou retomada, com a inserção do novo, pertinente aos novos tempos, imprimindo sua marca, coerente com o mundo em que vive. A linguagem utilizada nas moralidades é mais familiar a seu público: em vez de manter uma escrita em verso, Carter escreve as moralidades em prosa. E, em alguns momentos, podemos observar que ela opta por realizar alterações que tornam o texto mais pertinente a sua época, como veremos em sua tradução da moralidade do conto "O Barba Azul".

Ao transformar Perrault em relação, por exemplo, ao que é dito nas moralidades, Carter está sendo propriamente perraultiana, isto é, uma narradora de seu tempo, que não omite ideias e valores de sua época, mas sim as transmite, ainda que por meio de nuances em sua tradução. Vejamos, então, o conto “La Barbe Bleue" de Perrault e a estratégia tradutória de Carter em "Bluebeard", observando especificamente um detalhe na moralidade traduzida.

\footnotetext{
${ }^{15}$ No original: She found Perrault's contes congenial to her own Project, and the choices that she made in her translation further enabled her to reclaim the genre at a time when the fairy tale was a hotly debated subject in feminist circles.

${ }^{16}$ No Brasil, por exemplo, as moralidades de Perrault irão aparecer em livros infantis traduzidos apenas a partir do final do século XX em diante. Antes disso, traduções ou adaptações dos Contos da Mamãe Gansa eram apresentadas excluindo essa parte constitutiva do texto de Perrault. (OLIVEIRA, 2020)
} 
"O Barba Azul" de Perrault é um conto adaptado da tradição oral, no qual vemos a história da jovem que se casa com um homem muito rico que já havia sido casado com outras mulheres, das quais não se sabia o paradeiro. Logo após o casamento, Barba Azul diz que precisa fazer uma viagem e que a jovem esposa poderia explorar a casa como quisesse, convidando as amigas, abrindo os aposentos e até mesmo os cofres da casa. Ela só não poderia usar uma pequena chave que abriria o cabinet ao final da galeria dos aposentos. A mulher, entretanto, não resiste à curiosidade e abre a porta do gabinete, descobrindo os corpos de várias mulheres degoladas. A jovem não consegue limpar a pequena chave, que caíra ao chão coberto de sangue. Único elemento mágico do conto de Perrault, indelevelmente marcada pelo sangue, a chave é a prova da desobediência da mulher. Ao retornar na mesma noite, descobrindo que a esposa havia tentado entrar no gabinete, o marido anuncia que ela terá o mesmo destino das outras mulheres. A jovem pede que Barba Azul lhe conceda algum tempo para rezar, e assim seus irmãos chegam e conseguem salvá-la. Ao final, a jovem viúva herda toda a riqueza de Barba Azul, ajuda os irmãos e casa-se com um "bom homem”.

A história de Perrault já é uma forma de reescrita do conto, uma vez que o escritor transforma algumas passagens características da tradição da oralidade, por exemplo, inserindo o elemento cristão e retirando elementos mágicos ou ritualísticos. Em versões populares, a heroína avisava os irmãos por intermédio de um animal mensageiro, como um pássaro falante ou um cãozinho levando um bilhete (SORIANO, 2012, p.164), havendo portanto elementos mágicos (além da chave encantada) permeando a história. Em versões anteriores, quando Barba Azul anuncia que irá matar a esposa, ocorria uma espécie de ritual, no qual ele mandava a mulher vestir seu vestido de noiva ou os seus mais belos trajes para ser morta. Ela, então, em seu quarto, ia se vestindo e se despindo, enumerando os vestidos, sempre dizendo faltar vestir ainda mais um, gerando uma progressão da emoção dramática (p.165). Já em Perrault, inserindo o elemento cristão, esse ritual é substituído pelo momento em que a mulher pede ao marido para rezar antes de morrer, tentando ganhar tempo até a chegada dos irmãos. Por fim, Perrault insere sua marca autoral, duas moralidades em verso, tecendo seus comentários a respeito da história contada. 
Em sua tradução voltada a um público infantil, conforme comentado, Carter mantém o enredo e a concisão da linguagem vistos no texto de Perrault, utilizando, entretanto, uma linguagem mais contemporânea e um vocabulário familiar a seu público, notadamente elaborando frases mais sucintas, condizentes com uma história popular, e escrevendo as moralidades em prosa. Na primeira moralidade de "Bluebeard", temos uma passagem representativa da postura de Carter em sua tradução. Vejamos a moralidade em verso de Perrault (seguida da tradução para o português de Leonardo Fróes, utilizada aqui como guia de leitura) e a tradução em prosa de Angela Carter para o inglês.

MORALITÉ

La curiosité malgré tous ses attraits,

Coûte souvent bien des regrets;

On en voit tous les jours mille exemples paraître.

C'est, n'en déplaise au sexe, un plaisir bien léger;

Dès qu'on le prend il cesse d'être,

Et toujours il coûte trop cher.

(PERRAULT, 2013, grifos meus, p. 154)

MORAL

A curiosidade, com seu deslumbramento,

Causa muito arrependimento;

Há mil exemplos, todos os dias, a aparecer.

É, que a mulher me perdoe, um prazer tão raro

Que, satisfeito, deixa de ser

E sempre custa muito caro.

(PERRAULT, 2015, “O Barba Azul”, grifos meus, p. 16)

MORAL

Curiosity is a charming passion but may only be satisfied at the price of a thousand regrets; one sees around one a thousand examples of this sad 
truth every day. Curiosity is the most fleeting of pleasures; the moment it is satisfied, it ceases to exist and always proves very, very expensive. ${ }^{17}$ (PERRAULT, 2008, grifos meus, p.10)

Como já observado, Perrault era um escritor que fazia uso da ironia e da crítica social aos costumes de seu tempo. A referência à "mulher" em sua moralidade pode gerar a interpretação de uma visão sexista (a tentação da curiosidade vista como uma característica do sexo feminino), e Carter retira qualquer possibilidade de leitura atravessada por essa perspectiva. Em sua tradução, não há referência ao sexo feminino, como visto no trecho grifado acima.

Aqui cabe observar que Perrault poderia estar simplesmente usando de ironia para criticar o posicionamento de seus adversários no campo da literatura e das ideias, tais como Boileau, este sim um crítico da atitude de mulheres que buscavam o conhecimento (HENNARD DUTHEIL DE LA ROCHÈRE, 2013, p.125). Como é visto no conto de Perrault, a mulher, que seria punida por sua curiosidade, consegue livrar-se do mesmo destino das mulheres mortas exatamente por ter ousado descobrir o mundo em que vivia. Nesse sentido, a curiosidade adquire uma valência positiva.

Em seu projeto tradutório dos contos de Perrault voltado a um público infantil (CARTER, 2008, p.76), Carter realiza uma leitura do autor considerando tratar-se de um contador de histórias, as quais possuem uma função moral (e não moralizante), em que o narrador revela o mundo tal como é, sempre com um olhar crítico ou irônico ao final. Conforme Martine Hennard Dutheil de la Rochère enfatiza:

O trabalho de tradução trouxe uma consciência da agência do tradutor como mediador e re-criador, e Carter ao mesmo tempo descobriu a consistência histórica, densidade textual e ambivalência de direcionamento (crianças e adultos) dos aparentemente simples contos de Perrault. Ela não pôde transmitir toda essa complexidade em sua tradução, mas a explorou mais profundamente em suas reescritas. A câmara sangrenta pode assim ser vista como continuação de Os contos de fadas de Charles Perrault e

\footnotetext{
${ }^{17}$ MORAL

A curiosidade é uma paixão encantadora, mas só pode ser saciada ao preço de muitos arrependimentos; a gente vê a nossa volta mil exemplos dessa triste verdade todo dia. A curiosidade éo mais fugaz dos prazeres; no momento em que é saciada, deixa de existir e sempre se mostra muito, muito cara.
} 
contraponto aos mesmos, ainda mais porque os dois projetos foram realizados mais ou menos simultaneamente. ${ }^{18}$ (HENNARD DUTHEIL DE LA ROCHÈRE, 2013, p.3)

Se, na tradução dos contos de Perrault, Carter realiza transformações sutis condizentes com o público a que se dirige, em sua criação literária desenvolvida concomitantemente ao projeto tradutório, ela consegue explorar as potencialidades existentes na obra de Perrault, como veremos em "A câmara sangrenta".

\section{A câmara sangrenta da cultura patriarcal}

Trazendo à cena um Marquês, colecionador de arte e de mulheres reificadas como objeto de arte, na França do decadentismo fin de siècle, The Bloody Chamber pode ser visto como uma metáfora para a representação da mulher na arte e na cultura ocidentais. Enquanto em "La Barbe Bleue" ou em "Bluebeard" temos um conto em que o tema da curiosidade é trazido aos leitores como o motivo da punição da heroína, na reescrita autoral de Carter, a curiosidade da personagem, uma jovem pianista de dezessete anos, narradora de sua própria história, propicia a descoberta de um mundo, de uma cultura e sociedade, a partir de seu casamento com o Marquês. A curiosidade e o desejo da jovem instigam o leitor a tornar-se um "desbravador da câmara sangrenta da cultura patriarcal" 19 (HENNARD DUTHEIL DE LA ROCHÈRE, 2013, p. 111).

Angela Carter muda o foco do problema: da curiosidade da mulher como uma traição para a construção de um Barba Azul como um esteta do crime. Independentemente da curiosidade da esposa, esse homem, colecionador de arte e de mulheres-objeto-de-arte, irá agir para manter seu domínio sobre as mulheres, reificando-as. A crítica à sociedade que torna o feminino objeto do olhar masculino é evidente não apenas no enredo, mas

\footnotetext{
${ }^{18}$ No original: The work of translation brought an awareness of the agency of the translator as mediator and re-creator, and Carter simultaneously discovered the historical thickness, textual density, and dual mode of address (children and adults) of Perrault's deceptively simple tales. She could not convey all this complexity in her translation but would explore it more fully in her rewritings. The Bloody Chamber can therefore be seen as the continuation of and counterpoint to The Fairy Tales of Charles Perrault, all the more so because the two projects were carried out more or less simultaneously.

${ }^{19}$ No original: a curious explorer of the bloody chamber of patriarchal culture.
} 
em detalhes ao longo de todo o conto, no qual vemos uma galeria de obras e autores que retratam a mulher como objeto a ser sacrificado ou apreciado e devorado pelo olhar masculino. Duas das figuras dentre as mais representativas do mundo do Marquês são o quadro do martírio de Santa Cecília e a gravura de Félicien Rops, “Ma fille, Monsieur Cabanel!", na qual podemos ver uma menina magra e nua, usando apenas botas, luvas e um chapéu, ao lado da mãe que a oferece a Monsieur Cabanel (e ao apreciador da obra de arte).

Dentre as muitas possibilidades de análise, três aspectos do conto são destacados aqui para ressaltar a perspectiva feminista de Carter: 1) a jovem é a narradora de sua própria história; 2) Barba Azul torna-se um esteta do crime, um colecionador de arte; uma arte representativa do domínio do olhar masculino sobre a mulher, vista sempre como objeto; 3) a salvação ocorre pela figura feminina, a mãe, e não pelos irmãos. Vejamos:

\footnotetext{
Ele me despiu, gourmand que era, como se estivesse despindo as folhas de uma alcachofra [...] E quando nada além do meu escarlate e palpitante núcleo permanecia, vi no espelho a imagem viva de uma gravura de Rops da coleção que ele tinha me mostrado quando o nosso noivado nos permitira ficar juntos sozinhos... Uma criança com os membros franzinos, nua à exceção das botas de botão e das luvas, protegendo o rosto com a mão, como se seu rosto fosse o último repositório da sua modéstia; e o velho devasso de monóculo que a examinava, membro por membro. Ele em sua alfaiataria em Londres; ela, nua como uma costeleta de cordeiro. $\mathrm{O}$ mais pornográfico de todos os confrontos. E assim o meu comprador desembrulhava seu produto. E, como na ópera, quando eu tinha visto pela primeira vez a minha carne em seus olhos, fiquei horrorizada ao sentir que algo se agitava em mim. (CARTER, 2017, p.28)
}

A jovem narradora nos revela esse mundo que vai descobrindo, um mundo de contrastes e contradições, da elegância de traços e pinceladas de obras que retratam opressão, da necessidade de um casamento para escapar à pobreza ao desejo que irrompe nas relações de poder. A jovem é o próprio quadro vivo, tableau vivant, observado pelo leitor, prestes a se tornar uma natureza morta, nature morte, pelas mãos do Marquês. Assim como no trecho acima, todo o conto é permeado por referências a obras de arte, quadros, livros, óperas, em que a mulher se encontra reificada, sendo olhada por 
aquele que a possui. O Marquês exerce total controle sobre a imagem e a identidade da mulher, desde o jogo de espelhos no quarto do casal às roupas e joias usadas pela jovem.

É nessa política de representação sexual, de um domínio masculino sobre a vida da mulher, que o Marquês coleciona suas mulheres estetizadas em forma de arte. A primeira, uma modelo retratada por vários pintores, é exposta em sua galeria da câmara sangrenta apenas com seu crânio "suspenso por um sistema de cabos invisíveis, de modo que parecia se pendurar, desencarnado, [...] coroado com uma grinalda de rosas brancas e um véu de renda, [em sua] imagem final" (CARTER, 2017, p.49). A segunda esposa, uma cantora de ópera, é exposta "completamente nua, sob um fino lençol de linho muito raro e precioso" (p.49), embalsamada, e em sua garganta a marca azul dos dedos de seu estrangulador, que a silenciara para sempre. A última esposa, uma condessa romena, encontrava-se em uma câmara de tortura, a Donzela de Ferro, trespassada "por uma centena de espigões, aquela filha da terra dos vampiros" (p.50). A quarta esposa, a jovem pianista, teria o seu lugar nessa exposição macabra de corpos de mulheres tão enaltecidas por sua beleza, talento, fama ou inocência quanto brutalizadas por uma sociedade que domina, oprime, silencia e mata as mulheres. Carter expõe sem pudor as belas artes que representam tal domínio. Para a jovem pianista resta sua identificação com Santa Cecília, patrona dos músicos, condenada à decapitação por sua pregação do cristianismo.

Mas se os jogos visuais e das relações de poder estão estabelecidos desde tempos imemoriais, Carter faz questão de invertê-los nessa história. As figuras femininas são as protagonistas, seja ao contar a história pela sua própria perspectiva - a jovem narradora - seja trazendo a força da mulher que não se deixa dominar pelas regras do patriarcado, representada pela mãe da jovem. Essa mulher corajosa e "selvagem" (CARTER, 2017, p.66), que sabia o preço a ser pago por suas escolhas, tendo se casado por amor e enfrentado a pobreza, é quem irá salvar a filha de seu destino. No clímax da história, a jovem narradora, aludindo à Medusa, traz o poder visual para as mulheres. "E meu marido ficou imóvel, como se ela fosse Medusa, a espada ainda erguida sobre sua cabeça como naqueles quadros animados do Barba 
Azul que podemos ver em caixas de vidro nas feiras" (CARTER, 2017, p.6667). Paralisado ao ver a mãe da jovem, o Marquês acaba sendo morto por ela.

\section{Considerações finais}

Nas limitações de escopo deste artigo, buscou-se abordar a relação inextricável entre tradução e criação literária em Carter, restringindo a análise à história de Barba Azul, traduzida e reescrita por ela a partir de Perrault. Compreendendo que Carter adota Perrault, assim como também realiza sua leitura íntima, como leitora-tradutora, de autores como Sade ou Baudelaire, dentre tantas outras referências presentes em suas obras e em diálogo permanente com suas ideias, a perspectiva adotada aqui propõe certo afastamento da noção de subversão adotada pela crítica, tal como observado em Zipes. Carter reconhece Perrault como um contador de histórias, as quais refletem o mundo tal como é, valorizando justamente certas características literárias do autor francês, tais como as moralidades, as quais não são ignoradas ou desprezadas por ela (CARTER, 2008, p.76-77). Trabalhando com as primeiras edições da obra de Perrault, Carter traz uma contribuição fundamental para os Estudos de Contos de Fadas, apresentando o autor francês aos leitores de língua inglesa, tanto em sua tradução dos contos como também no paratexto do livro publicado em 1977, analisando as características dos contos por ela traduzidos. Já sua reescrita autoral é vista aqui como a continuidade de uma leitura íntima, a partir da qual Carter faz as velhas garrafas explodirem, trazendo aos leitores histórias tão antigas contendo agora, no presente, uma infinidade de possíveis novas leituras. Mais do que subversivo, ou diferentemente disso, tal processo é uma forma de criação literária, uma poética translacional, em que estão interligadas a tradução e a recriação. Carter, traduzindo Perrault, possibilita que o cânone se mantenha, e reescrevendo-o, apresenta um contraponto; repetição e diferença.

\section{Referências}


CARTER, Angela. As infernais máquinas de desejo do Dr. Hoffman. Título original: The infernal desire machines of Dr. Hoffman. Tradução de Afonso Felix de Sousa. Rio de Janeiro: Rocco, 1988.

CARTER, Angela. Afterword. In: PERRAULT, Charles. Little Red Riding Hood, Cinderella, and Other Classic Fairy Tales of Charles Perrault. Tradução e posfácio de Angela Carter. Introdução de Jack Zipes. New York: Penguin, 2008.

CARTER, Angela. A Câmara Sangrenta e outras histórias. Título original: The Bloody Chamber and Other Stories. Tradução e prefácio de Adriana Lisboa. Ilustrações de Carla Barth. Porto Alegre: Dublinense, 2017.

COLLOGNAT-BARÈS, Annie; BRUNET, Dominique; DRONNE, Frédéric. Apresentação da edição francesa. In: PERRAULT, Charles. Contos de Charles Perrault. Tradução de Eliana Bueno-Ribeiro. São Paulo: Paulinas, 2016.

HAASE, Donald. Yours, Mine, or Ours? Perrault, Brothers Grimm, and the Ownership of Fairy Tales. In: TATAR, Maria (ed.). The Classic Fairy Tales. New York/London: Norton, 1999. p. 353-364.

HAASE, Donald. Preface. In: HAASE, Donald (ed.). Fairy Tales and Feminism: New Approaches. Detroit: Wayne State University Press, 2004. p. xii-xiv.

HAASE, Donald (ed.). The Greenwood encyclopedia of folktales and fairy tales. Connecticut/ London: Greenwood Press, 2008.

HENNARD DUTHEIL DE LA ROCHÈRE, Martine. Reading, Translating, Rewriting: Angela Carter's Translational Poetics. Detroit: Wayne State University Press, 2013.

MULVEY-ROBERTS, Marie. The arts of Angela Carter: a cabinet of curiosities. Manchester: Manchester University Press, 2019.

PERRAULT, Charles. Little Red Riding Hood, Cinderella, and Other Classic Fairy Tales of Charles Perrault. Tradução e posfácio de Angela Carter. Introdução de Jack Zipes. New York: Penguin, 2008. 
PERRAULT, Charles [et al.]. Contos de fadas de Perrault, Grimm, Andersen \& outros. Apresentação de Ana Maria Machado. Tradução de Maria Luiza X. de A. Borges. Vários ilustradores. Rio de Janeiro: Zahar, 2010.

PERRAULT, Charles. Contes. Édition critique Jean-Pierre Collinet. Folio classique. Paris, Gallimard, 2013.

PERRAULT, Charles. Contos da mamãe gansa ou histórias do tempo antigo. Tradução de Leonardo Fróes. Posfácio de Michel Tournier. Ilustrações: Milimbo. São Paulo: Cosac Naify, 2015.

OLIVEIRA, Anna Olga Prudente de. Histórias do tempo antigo com moralidades: uma análise das reescritas da obra de Charles Perrault no Brasil. Rio de Janeiro: Numa/PUC-Rio, 2020.

SORIANO, Marc. Les Contes de Perrault: Culture savante et traditions populaires. Paris : Gallimard, 2012 (1968).

ZIPES, Jack. Introduction. In: PERRAULT, Charles. Little Red Riding Hood, Cinderella, and Other Classic Fairy Tales of Charles Perrault. Tradução e posfácio de Angela Carter. Introdução de Jack Zipes. New York: Penguin, 2008.

\section{Resumo}

Este artigo discute a relevância da atividade tradutória para a criação literária de Angela Carter, analisando a obra The Bloody Chamber and Other Stories (A câmara sangrenta e outras histórias), criada a partir de contos de fadas, como os do autor francês Charles Perrault. Com base no conto The Bloody Chamber (A câmara sangrenta), inspirado na história de "Barba Azul", são discutidas questões relativas ao projeto de tradução da escritora inglesa e sua (re)escrita autoral a partir de uma perspectiva feminista, sendo estabelecida uma relação inextricável entre tradução e criação literária.

Palavras-chave: Estudos Feministas de Contos de Fadas; Angela Carter; Reescrita de contos de fadas; A câmara sangrenta 


\begin{abstract}
This article discusses the importance of the translation activity in Angela Carter's literary output, analysing the work The Bloody Chamber and Other Stories, which took inspiration from existing fairy tales, such as those published by the French author Charles Perrault. On the basis of the tale The Bloody Chamber, inspired by the story of "Bluebeard", the discussion addresses Carter's translation project and her (re)writing of the story from a feminist perspective, establishing an inextricable relation between translation and literary output.
\end{abstract}

Keywords: Feminist Fairy-Tale Studies; Angela Carter; Fairy tale rewritings; The Bloody Chamber 